\title{
Knowledge on cervical cancer prevention and HPV vaccination among female students in tertiary education centers in Batticaloa, Sri Lanka
}

\author{
Azeez $\mathrm{FMA}^{1}$, Naajeda $\mathrm{MJ}^{1}$, Luthah MFF${ }^{1}$, Jiyatha $\mathrm{ASF}^{1}$, Sivanjali $\mathrm{M}^{2}$, Karunakaran $\mathrm{KE}^{3}$
}

\begin{abstract}
:
Background: Carcinoma of cervix is common yet preventable.Sri Lankan young population is at risk. This study was conducted among the students attached to three non-conventional higher education institutions with reference to assessing the awareness, screening methods, Human Papilloma Virus (HPV) as causative factor and attitude towards HPV vaccination.

Methods: A validated questionnaire was used. Data were analyzed using SPSS 25 software.

Results: 120 females participated, age ranging 19 to 25 years.Seventy (57.5\%) participants were aware of the cervical cancer. Seventy percent of them were also aware HPV as causative factor. About half of the participants (50.8\%) were not aware of availability of cervical screening. Among those aware of the screening, about half reported the availability of both Pap smear and HPV testing. Totally about $87 \%$ were aware of the Pap smear. Sixty nine students [57.5\%] were 'not sure' of the availability of HPV vaccine and 58 of them stated 'unsure of vaccine received'. About $16 \%$ did not want to receive the vaccine. One third mentioned that the HPV Vaccine is available in Sri Lanka.

Conclusions: The awareness noted under $60 \%$ of the participants indicates the need for structured awareness programs to young population. Majority of participants were confused about the availability and whether they had received of HPV vaccine.
\end{abstract}

Key words:Cervical Cancer, Screening, Awareness, Higher Education, HPV Vaccine

\section{Introduction}

Carcinoma of cervix is the fourth common cancer affecting human health and the second most common female cancer world-wide ${ }^{1}$ causing significant morbidity and mortality. It is a sexually transmitted disease and association of Human Papilloma Virus (HPV) with carcinoma of cervix has been well established. ${ }^{2}$ Exposure to sex at teen age is a risk factor forHPV infection. 3 It has also been noted that in Sri Lanka the increasing tendency for the young population engaging in sexual activity and thus Sri Lankan Health sector had to consider adolescent health services with access to contraceptive services to this population. ${ }^{4}$ However, there is no clear evidence

1.Department of Primary Health Care, Faculty of HealthCare Sciences, Eastern University, Sri Lanka.

2.Department of Medical Education and Research, Faculty of Health-Care Sciences, Eastern University, Sri Lanka.

3.Department of Clinical Sciences, Faculty of Health-Care Sciences, Eastern University, Sri Lanka.

Corresponding author;

K E Karunakaran

email: karunakarank@esn.ac.lk

(D) https://orcid.org/0000-0001-7200-5239 that the usage of contraceptives such as male condoms confer protection against HPV infection. Furthermore, except for genital warts which is caused by a less virulent strain of HPV, the infection in female reproductive tract is asymptomatic and the more virulent strains cause changes in the infected cells. 5 In Sri Lanka the cervical screening services are currently available for women over 35 years of age. 6 However, this is a less popular procedure. Similarly, HPV vaccination also requires to be improved among the Sri Lankans. In this background it becomes essential to educatethe young population of the risk of carcinoma of cervix. This studywasconductedamong the students attending the non-conventional tertiary educational institutions in Batticaloa, Sri Lanka. The objectives of the study were to assess the knowledge and awareness of carcinoma of cervix among female students aged between $19-25$ years attending three selected centers with particular reference to;awareness of cervical cancer, HPV as causative factor,cervical screening methods and attitude towards HPV vaccination.

\section{Material and Methods}

This study was conducted in three tertiary educational institutions located in Batticaloa city namely Open University of Sri Lanka study center, E-Soft In- 
stitute and Blue Sky Campus. Female students between the age of 19 and 25 years were recruited. According to the data given from the institutions an average of 166 eligible study cohort was available in each institution. Reported studies indicated that the percentage of population aware of cervical cancer prevention by HPV vaccination was about $10.3 \% .7$ Thus, it was assumed the prevalence for these centers would be 0.103 . The sample size was calculated using Krejice and Morgan formula 8 at $95 \%$ confidence interval with the margin of error as 0.05 . Accordingly, sample size was calculated as 110 . We were able to recruit 120 students for this study since we expected about $10 \%$ non-responsiveness. A pretested self-administered questionnaire was used to obtain data. Ethical clearance was obtained from the Ethical Review committee of Faculty of Health-Care Sciences of Eastern University, Sri Lanka. Informed written consent was obtained from each participant. Pilot test was conducted among ten students to validate the questionnaire.Data were analyzed using SPSS 25 statistical software.

\section{Results}

A total of 120 female students took part in the study with age range of 19 -25 years (table 1 ). Forty students were recruited from each study center. Approximately $7 \%$ of them were married. All the students had studied up to G C E Advanced Level in their secondary school education however, $10 \%$ of them did not complete. Thus the educational qualification to the latter became G C E Ordinary level.

\section{Table 1:General Demographic Data of the study population}

\begin{tabular}{|c|c|c|}
\hline Variable & Number & Percentage \\
\hline \multicolumn{3}{|c|}{ Age group [years] } \\
\hline 19 & 62 & 51.7 \\
\hline $20-21$ & 36 & 30 \\
\hline $22-25$ & 22 & 18.3 \\
\hline \multicolumn{3}{|c|}{ Education level } \\
\hline GCE O/L & 12 & 10 \\
\hline GCE A/L & 108 & 90 \\
\hline \multicolumn{3}{|c|}{ Marital status } \\
\hline Single & 111 & 92.5 \\
\hline Married & 09 & 7.5 \\
\hline
\end{tabular}

70 (57.5\%) participants reported that they were aware of cervical cancer (Table 2). Seventy percent of them were aware that HPV as causative factor of the cancer.

Table 2: Awareness of cervical cancer and HPV as causative factor

\begin{tabular}{|llll|}
\hline & Yes & No & Do not know \\
\hline $\begin{array}{l}\text { Aware of cervical cancer } \\
\text { If 'Yes' (n=70): }\end{array}$ & $70(57.5 \%)$ & $50(42.5 \%)$ & \\
HPV as causative factor & $49(70 \%)$ & & $21(30 \%)$ \\
\hline
\end{tabular}

Exploring into the awareness about availability and the types of screening, about half of the participants (50.8\%) were not aware of such practice (Table 3 ). Among those aware of the screening, about half (49.2\%) reported the availability of both Pap smear and HPV testing. Approximately $87 \%$ of this cohort were aware of the Pap smear as an available screening method.

Table 3: Awareness on cervical screening: Response from participants

\begin{tabular}{|l|l|l|}
\hline \multirow{2}{*}{$\begin{array}{l}\text { Cervical screening is available in } \\
\text { Health sector }\end{array}$} & Yes & No \\
\cline { 2 - 3 } & $\mathbf{6 1 ( 5 0 . 2 \% )}$ & $\mathbf{5 9 ( 4 9 . 8 \% )}$ \\
\hline If 'Yes' (n=61): on method of screening; & \multicolumn{2}{|l|}{} \\
\hline Pap smear only & $\mathbf{2 3 ( 3 3 . 7 \% )}$ & - \\
\hline HPV testing only & $08(13.1 \%)$ & - \\
\hline Both & $30(49.2 \%)$ & - \\
\hline
\end{tabular}

Cervical screening is available in Health sector

With regard to assessing the participants' attitude towards the HPV vaccine (Table 4), new responses such as 'Not sure of vaccine available, unsure of vaccine received' were mentioned by majority of participants in the pilot study. The response 'Not sure of vaccine available' was included into the questionnaire replacing the statement 'do not know'. Sixty nine (57.5\%) participants responded to this and the majority among them (58) stated 'unsure of the vaccine received'. Thirty four (28\%) of the participants were eager to receive the vaccine and about $16 \%$ of the students (19) stated that they did not want to receive the HPV vaccine. One third of the participants mentioned that the Vaccine for HPV is available in Sri Lanka.

\section{Discussion}

Carcinoma of cervix isregarded as a sexually transmitted disease. Human papillomavirus (HPV) is the most common viral infection of the reproductive tract2 and is a renowned cause of cervical cancer but also other cancers including the vulva, anus, 
Table 4: Attitude towards the vaccine; Response from participants

\begin{tabular}{|ll|}
\hline Availability of HPV vaccine & Frequency \\
\hline Yes & $40(33.3 \%)$ \\
Not Sure & $69(57.5 \%)$ \\
No & $11(09.2 \%)$ \\
If 'Yes' & \\
Received the vaccine & 09 \\
Do not want to receive & 00 \\
Eager to receive & 31 \\
If 'Not sure' & \\
Eager to receive & 03 \\
Do not want to receive & 08 \\
Unsure of vaccine received & 58 \\
If 'No' & \\
Eager to receive vaccine & 00 \\
Do not want & 11 \\
\hline
\end{tabular}

vagina, penis, head and neck. ${ }^{9}$ Cervical cancer kills over 300,000 women worldwide annually and over 570,000 new cases are diagnosed each year. In developing countries this is the most common killer out of the female cancers. ${ }^{5,10}$ Despite this, the knowledge and attitudes towards this cancer among the population appear lower, especiallyamong the young.

In Sri Lanka an estimated 8.4 million women from the age 15 years onwards are at risk of developing carcinoma of cervix. Further, this cancer is the third leading cause of cancer deaths in females and the prevalence of virulent HPV in cases of cervical cancer is reported as $80.6 \%$.11The ICO/IARC Information Centre on HPV and CancerFact Sheet 2018on Sri Lanka ${ }^{11}$ reports that 'Current estimates indicate that every year 1136 women are diagnosed with cervical cancer and 643 die from the disease'. Thus, prevention is the strategy. Thus, cervical screening, HPV vaccination and safe sexual behavior with one faithful partner hold the key to minimize the incidence of cervical cancer. Awareness among the young people with regard to these factors would play a major role in achieving this goal.

This study was thus focused on the young females who had the eagerness for higher studies after secondary school education, but not gainedentrance to a conventional university.

Previous studies of this nature had been carried out often among the university students and thus we aimed to conduct our study among the other students. In this study we were able to find out that $57.5 \%$ of the participants had known that there ex- ists cancer of cervix. Studies done in Sri Lanka among the undergraduate students in Kandy (57.7\%)12 and at Eastern University, Sri Lanka (59.4\%)13also showed similar rates. Although similar results have been found in the neighboring countries such as India (66\%) and Nepal (58.6\%) in the study reported in $2011^{12}$, subsequent studies showed improved results. A study conducted among students in Rajarata University of Sri Lanka in 2015 revealed that $72 \%$ of students (both males and females) were aware of cervical cancer. ${ }^{14}$ In a study done at a private university in India in 2015, the awareness of cervical cancer among girl students was found to be $82.45 \% 15$ with Biology stream students showed significantly higher knowledge. Another study reported in 2019 in Zimbabwe showed $87.47 \%$ of students of both sex from the universities and high schools ${ }^{16}$ concluding that 'young people in Zimbabwe have an idea about cervical cancer and the seriousness thereof'.

Our study found that $70 \%$ of those aware of the cervical cancer link with HPV. Among the studies done in Sri Lanka, in the Rajarata University study $47 \%$ of the participants identified HPV as a causative factor of carcinoma of cervix ${ }^{14}$. The Kandy study assessed the knowledge of HPV among the undergraduates; $48.5 \%$ of Sri Lankan participants reported to have such knowledge. The same study reported that $49 \%$ of Indian and $52.5 \%$ of Nepali participants had such knowledge. ${ }^{12}$ The other studies from India and Zimbabwe reported $45.6 \%$ and $47 \% .15,16$ respectively indicating that less than half the young student population has the knowledge of HPV and its link to carcinoma of cervix. The study conducted among the students in the public and private universities in Lahore, Pakistan (reported in 2016)9revealed that $57 \%$ (223) of the participants have heard about HPV. Except a few, all of them (215) reported that HPV as causative factor of cervical cancer.

Cervical screening has been an established practice world-wide with different formats in different countries. In Sri Lanka visualizing the cervix and Pap smear has been the practice in women of 30 years and older, once in every five year frequency. $51 \%$ of the participants reported the availability of cervical screening in the Sri Lankan health system; half of them reported of availability of both Pap smear and HPV testing and in total, about $87 \%$ had known that Pap smear as the screening method (Table 3). The Eastern University study ${ }^{13}$ showed $52 \%$ of the participants had adequate knowledge on cervical screening. The Zimbabwe study ${ }^{16}$ reported that the 'study has shown that the knowledge of the screening services and their availability is very low even among young women between the ages of 21 to 24 years'. It should be noted that in Sri Lanka, although Pap smear has been an established practice, coverage is rather small. It should also be noted that the HPV DNA test- 
ing is not routinely done in Sri Lanka but available in the private labs at high cost.

Vaccination against HPV is the key to primary prevention of women contracting cervical cancer. Vaccine could give $95 \%$ protection against cancer causing strains $^{2}$. This type of immunization should be given to young girls before the exposure to sexual activities. In this study the knowledge of the availability of vaccine for HPV in the health system has been known to one third of the participants (Table 4). The Rajarata study ${ }^{14}$ also showed a similar result of $35 \%$. However, the Eastern University study showed lower rates; about $18 \%$ of the participants had satisfactory knowledge about the vaccine and mixed results with regard to the knowledge on its availability. ${ }^{13}$ The Indian study ${ }^{15}$ showed that $44 \%$ of girls and $31.6 \%$ of boys had the knowledge of HPV vaccine; The Pakistan study ${ }^{9}$ reported that about $45 \%$ of students stated that HPV can be prevented by vaccination. The same study also reported that 'almost $64 \%$ rejected the statement that HPV vaccine prevents cervical cancer'.

The interesting finding came from this study is the fact of participants were 'not sure' HPV vaccine available in Sri Lanka and also of that they are 'unsure of having received the vaccine'. This type of confusion the students have cannot be considered as unusual. It is because Sri Lanka has a well-structured immunization program.This they receive at the tender age when their understanding about the vaccine given seem limited.

\section{Conclusion}

The present study was done among the students receiving the higher education in institutions outside the conventional Sri Lankan University system. The study noted higher percentage of knowledge and awareness with regard to various aspects connected to the cervical cancer prevention comparing to the previous studies. However, such awareness could be noted under $60 \%$ and this indicates the need for structured awareness programs to reach the entire young population on cervical cancer.

Authors' contribution: Concept for the research work was conceived by FMAA, MJN, MFFL, ASFJ who were also involved in literature survey and data collection. KEK was involved in data analysis, literature search and paper writing and SM contributed in statistical analysis and paper writing.

\section{References:}

1. Bray, F., Ferlay, J., Soerjomataram, I., Siegel, R. L., Torre, L. A., \& Jemal, A. (2018). Global cancer statistics 2018: GLOBOCAN estimates of incidence and mortality worldwide for 36 cancers in 185 countries. CA: A Cancer Journal for Clinicians, 68(6), 394-424. https://doi.org/10.3322/caac.21492

2. World Health Organization. (2019). Human papillomavirus (HPV) and cervical cancer. Retrieved January 24, 2019, from World Health Organization website: https://www.who.int/news-room/factsheets/detail/human-papillomavirus-(hpv)-andcervical-cancer

3. Panatto, D., Amicizia, D., Trucchi, C., Casabona, F., Lai, P. L., Bonanni, P., Gasparini, R. (2012). Sexual behaviour and risk factors for the acquisition of human papillomavirus infections in young people in Italy: suggestions for future vaccination policies. BMC Public Health, 121. Panat(1), 623. https:// doi.org/10.1186/1471-2458-12-623

4. Vithana, P. V. S. . (2018). Adolescent Sexual and Reproductive Health Services in Sri Lanka: Needs, Challenges and Responses. Sri Lanka Journal of Obstetrics \& Gynaecology, 40(1).

5. Burd, E. M. (2003). Human papillomavirus and cervical cancer. Clinical Microbiology Reviews, 16(1), 1-17. https://doi.org/10.1128/cmr.16.1.117.2003

6. Kumara, W. G. N., \& Dasanayake, D. L. W. (2017). Cervical cytology screening: knowledge attitudes and behaviour of public health midwives in an urban district in Sri Lanka. Sri Lanka Journal of Obstetrics and Gynaecology, 39(1), 16. https://doi. org/10.4038/sljog.v39i1.7807

7. Wong, L.P., (2011). Knowledge and Attitudes About HPV Infection, HPV Vaccination, and Cervical Cancer Among Rural Southeast Asian Women. Int.J. Behav. Med.18, 105-111. https://doi. org/10.1007/s12529-010-9104-y

8. Krejcie, R. V., \& Morgan, D. W. (1970). Determining sample size for research activities. Educational and Psychological Measurement, 30, 607-610. https://doi.org/10.1261/rna.2763111

9. Khan, T. M., Buksh, M. A., Rehman, I. U., \& Saleem, A. (2016). Knowledge, attitudes, and perception towards human papillomavirus among university students in Pakistan. Papillomavirus Research (Amsterdam, Netherlands), 2, 122-127. https:// doi.org/10.1016/j.pvr.2016.06.001

10. Varughese, J., \& Richman, S. (2010). Cancer care inequity for women in resource-poor countries. Reviews in Obstetrics \& Gynecology, 3(3), 122132. Retrieved from https://pubmed.ncbi.nlm. nih.gov/21364864 
11. ICO/IARC Information Centre on HPV and Cancer. (2019). Sri LankaHuman Papillomavirus and Related Cancers, Fact Sheet 2018. Retrieved from https:// hpvcentre.net/statistics/reports/LKA_FS.pdf

12. Joy, T., Sathian, B., Bhattarai, C., \& Chacko, J. (2011). Awareness of Cervix Cancer Risk Factors in Educated Youth: A Cross-Sectional, Questionnaire Based Survey in India, Nepal, and Sri Lanka. Asian Pacific Journal of Cancer Prevention, 12(7), 1707-1712. Retrieved from http://journal.waocp. org/article_25770.html

13. Fasry, A., Dissanayake, D., Wanasinghe, D., Jenitha, J., Damayanthi, R. \& Karunakaran, K. (2020). Awareness of Cervical Cancer and Its Prevention: A Survey at Eastern University, Sri Lanka. Journal of Health Care and Research, 1(2), 55-64. https:// doi.org/doi.org/10.36502/2020/hcr.6162

14. Östh, J. (2015). Knowledge of Human Papilloma Virus, Cervical Cancer and Cytological Screening and Attitudes towards and Practices of Screening among Undergraduate students at Rajarata University, Sri Lanka : A cross-sectional study(Uppsala University Publications). Retrieved from http:// uu.divaportal.org/smash/get/diva2:821101/FULLTEXT01.pdf

15. Rashid, S., Labani, S., \& Das, B. C. (2016). Knowledge, Awareness and Attitude on HPV, HPV Vaccine and Cervical Cancer among the College Students in India. PloS One, 11(11), e0166713-e0166713. https://doi.org/10.1371/journal.pone.0166713

16. Mapanga, W., Girdler-Brown, B., \& Singh, E. (2019). Knowledge, attitudes and practices of young people in Zimbabwe on cervical cancer and HPV, current screening methods and vaccination. BMC Cancer, 19(1), 845. https://doi.org/10.1186/ s12885-019-6060-z 